\title{
Stability Analysis using Crossover GxE interaction in Mungbean [Vigna radiate (L.) R. Wilczek] in the hot -arid Climate of Rajasthan, India
}

\author{
Om Vir Singh*, Neelam Shekhawat, Kartar Singh and A.K. Singh
}

National Bureau of Plant Genetic Resources, Regional Station, Jodhpur, India

*Corresponding author

\begin{tabular}{|c|c|}
\hline & A B S T R A C T \\
\hline Keywords & \multirow{4}{*}{$\begin{array}{l}\text { Thirty eight accessions of mungbean along with checks were evaluated in six seasons i.e. } \\
\text { Summer and Kharif of the year } 2012,2013 \text { and } 2014 \text { for eight quantitative traits and data } \\
\text { were subjected to regression analysis and also the analysis to detect the presence of } \\
\text { crossover and non-crossover interactions. Six accessions IC } 103059 \text {, IC } 103207 \text {, IC } \\
103238 \text {, IC } 103300 \text {, IC } 333213 \text { and IC } 370739 \text { were identified to be promising using } \\
\text { regression analysis, whereas nine accessions IC } 39587 \text {, IC } 103204 \text {, IC } 103300 \text {, IC } 103785 \text {, } \\
\text { IC } 103788 \text {, IC } 103821 \text {, IC } 333153 \text {, IC } 333213 \text { and IC } 338902 \text { against standard check GM } \\
4 \text { were identified as potential ones by using crossover and non-crossover interactions } \\
\text { concept. Of these accessions IC } 103300 \text { and IC } 333213 \text { have been identified as high } \\
\text { yielding accessions having specific adaptability and responsiveness to specific } \\
\text { environment both by regression analysis and crossover and non-crossover interactions } \\
\text { concept. }\end{array}$} \\
\hline $\begin{array}{l}\text { Mungbean, Hot arid } \\
\text { climate, , ccession } \mathrm{x} \\
\text { environment interaction, } \\
\text { Crossover and non- } \\
\text { crossover interactions, } \\
\text { Regression analysis }\end{array}$ & \\
\hline Article Info & \\
\hline $\begin{array}{l}\text { Accepted: } \\
\text { 08 June } 2018 \\
\text { Available Online: } \\
\text { 10 Julv } 2018\end{array}$ & \\
\hline
\end{tabular}

\section{Introduction}

Productivity of mungbean in the hot- arid climate has always not been comparable to the normal climatic condtions. mungbean is cultivated during Summer and Kharif seasons in India but there has not been any specific variety for the Summer season. However, a few varieties have been developed for the Summer season but they are not suitable for hot- arid climate. Thus, farmers grow the varieties of Kharif season in Summer season. To enhance productivity and production of mungbean it is advocated that breeders should look for environment specific varieties which are capable of giving high yield. This becomes more important in case of arid grain legumes to breed for their responsiveness to specific environment.

Keeping in view the above, the present investigation was carried out over years during Summer and Kharif seasons in the hot- arid climate of Rajasthan to identify season specific accessions in mungbean using regression analysis (Eberhart and Russell, 1966 and Perkins and Jinks, 1968) and cross and non-crossover interactions concept (Gail and Simon, 1985). Earlier information on this aspect in mungbean germplasm is not available. 


\section{Materials and Methods}

Thirty eight diverse accessions collected in different years from different place from India and received from abroad also along with best performing local checks i.e. GM 4, RMG-492 and SML-668 were evaluated in a randomized block design with three replications over three years during Summer and Kharif seasons at Regional Station of National Bureau of Plant Genetic Resources, Jodhpur. Thus, evaluation was done broadly in six environments. In each environment plots consisted of four rows of 3 $m$ length with row to row and plant to plant distances of 30 and $10 \mathrm{~cm}$., respectively. Recommended doses of $\mathrm{P}_{2} \mathrm{O}_{5} @ 25 \mathrm{~kg} / \mathrm{ha}$ and $\mathrm{N}_{2} @ 15 \mathrm{~kg} / \mathrm{ha}$ were also applied at the time of sowing. Recommended packages and practices were followed to raise good crop. The data were recorded on five randomly taken plants from middle rows of each plot in each environment on seed yield/plant $(\mathrm{g})$, biological yield/plant (g), harvest index (direct values were used for statistical analysis), number of seeds/pod (average of 10 randomly taken pods from each plant), number of pods per plant, number of branches per plant, number of pod per clusters per plant and 100seed weight (g) and data were analyzed separately for each environment. Adjusted progeny means were used for the combined analysis and for the traits exhibiting the presence of $\mathrm{g} x \mathrm{e}$ interaction. Regression analysis and analysis to detect the presence of crossover and non-crossover interactions were carried out as per Eberhart and Russell (1966), Perkins and Jinks (1968) and Gail and Simon (1985).

\section{Results and Discussion}

Analysis of variance revealed significant differences among accessions for the eight traits in all six seasons. The combined analysis revealed the presence of $\mathrm{g} x$ e interaction for seed yield/plant (g), biological yield/plant $(\mathrm{g})$, harvest index (direct values were used for statistical analysis), number of seeds/pod (average of 10 randomly taken pods from each plant), number of pods per plant, number of branches per plant, number of pod per clusters and 100-seed weight (g). Regression analysis enables breeders to select desirable accessions with respect to the responsiveness and stability in different environments. In the studied materials the accessions IC 103238, IC 103059, IC 103207, IC 370739 IC 333213 and IC 103300 had above average performance and responsiveness with respect to seed yield/plant using regression analysis (Table 1). Among these high yielding accessions IC 103238, IC 103059, IC 103207 and IC 370739 can be designated as stable ones with average responsiveness. Though the accessions IC 333213 and 103300 are above average yielder and also have shown above average responsiveness coupled with instability. Accession IC 333213 and IC 103300 were highest yielder during Kharif 2012 and Kharif 2014 respectively followed by IC 370739 (Kh., 2012), IC 103238 (Kh., 2012), IC 103059 (Kh., 2014) and IC 103207 (Kh., 2013) and were significantly superior to the best check GM 4. The accession IC 333213 showed above average performance along with instability for Seed yield per plant, biological yield/plant, 100-seed weight, number of pods per plant and number of branches per plant being the best performance of this accession for these traits again in Kharif 2012 and accession IC 103300 showed above average performance along with instability for seed yield per plant, biological yield/plant, number of pods per cluster, number of cluster per plant and number of branches per plant being the best performance of this accession for these traits again during Kharif 2014.

The regression technique describes the response pattern of individual accession without differentiating the kind of $\mathrm{g} x \mathrm{e}$ 
interaction involving change in magnitude of response or direction among the accessions (Baker, 1988 and Virk and Mangat (1991). Baker (1988) described a test, which was initially proposed by Gail and Simon (1985) and illustrated its application to test the kind of interaction in crop plants. The concept of crossover and non-crossover interaction is important in decision making relating to crop improvement strategies (Baker, 1988), since the presence of crossover interaction is substantial evidence in favour of breeding for specific adaptation to certain situations. Baker (1988) further suggested that in the absence of crossover interaction there is little substance for argument in the favour of breeding for adaptation to specific environment. The accessions exhibiting crossover interaction against a standard variety can be said to have specific adaptability and can replace that standard variety in the specific environments. The existence of prior scientific basis to explain crossover interaction is crucial (Peto, 1982). Thus, it is advantageous to define the varietal combinations among which one has to look for qualitative interaction in advance. There will be enormous multiplicity of all possible varietal pairs for detection of crossover interaction if there is no prior basis for comparison. Such a practice will greatly increase the experiment-wise error rate. In the present case the new accessions were therefore, compared with the best check GM 4 for detection of crossover interaction since the aim was to find a suitable alternative to GM 4 .

The $\mathrm{H}$ (heterogeneity of response) and $\mathrm{Q}^{+}$and $\mathrm{Q}^{-}$(for the presence of crossover interaction) against the standard variety GM 4 were estimated for all the 37 accessions for the traits exhibiting the presence of $\mathrm{g} x \mathrm{e}$ interaction, i.e., seed yield/plant (g), biological yield/plant (g), harvest index, number of seeds/pod, number of pods per plant, number of branches per plant, number of pod per clusters per plant and 100-seed weight $(\mathrm{g})$ and their significance was tested (Baker, 1984). The accession exhibiting either significant $\mathrm{H}$ or $\mathrm{Q}^{+}$and $\mathrm{Q}^{-}$are given in Table 2 . For seed yield/plant $H$ was significant for the 34 accessions against GM 4. The presence of crossover interaction was observed for thirty accessions, IC 39550, IC 39574, IC 39587, IC 103190, IC 103204, IC 103219, IC 103243, IC 103245, IC 103300, IC 103785, IC 103788, IC 103821, IC 418452, EC 520034, EC 520035, EC 520036, IC 285192, IC 305292, IC 311397, IC 324021, IC 325752, IC 333153, IC 333213, IC 338850, IC 338902, IC 369790, IC 370714, IC 373426, G-492 and SML-668 for seed yield/plant against GM 4. The 27 accessions i.e. IC 39550, IC 39574, IC 103059, IC 103190, IC 103204, IC 103207, IC 103224, IC 103238, IC 103245, IC 103300, IC 103788, IC 103821, IC 103981, IC 370739, IC 418452, EC 520034, EC 52500, EC 520036, IC 305292, IC 324021, IC 333153, IC 333213, IC 338850, IC 338902, IC 369790, IC 370714 and IC 373426 exhibited the presence of crossover interaction for biological yield/plant and thirty five accessions namely, IC 39550 , IC 39574, IC 39583, IC 39587, IC 103059, IC 103190, IC 103204, IC 103207, IC 103219, IC 103224, IC 103238, IC 103243, IC 103245, IC 103785, IC 103788, IC 103821, IC 103981, IC 370739, IC 418452, EC 520034, EC 52500, EC 520036, IC 285192, IC 305292, IC 311397, IC 324021, IC 325752, IC 333153, IC 338850, IC 338902, IC 369790, IC 370714, IC 373426, G-492 and SML-668 exhibited the presence of crossover $\mathrm{g} x$ e interaction for harvest index. The 27 accessions exhibited the presence of crossover interaction for seeds/pod for the accessions namely, IC 39574, IC 39587, IC 103059, IC 103190, IC 103204, IC 103207, IC 103219, IC 103224, IC 103243, IC 103785, IC 103788, IC 103821, IC 370739, IC 418452, EC 520034, EC 52500, EC 520036, IC 305292, IC 324021, IC 325752, IC 333153, IC 338850, IC 338902, IC 369790, IC 370714, IC 373426 and SML-668. 
Table.1 Heterogeneity $(\mathrm{H})$ test of response for the comparison of mean seed yield/plant (g) against the standard variety GM 4 along with $\mathrm{Q}^{+}$and $\mathrm{Q}^{-}$values for crossover interaction and adaptability parameters for the accessions

\begin{tabular}{|c|c|c|c|c|c|c|}
\hline \multirow[t]{2}{*}{ Accession } & \multicolumn{3}{|c|}{ Adaptability Parameters } & \multicolumn{3}{|c|}{ Against GM 4} \\
\hline & $\mathrm{u}+\mathrm{d}_{\mathrm{i}}$ & $\mathrm{B}_{\mathrm{i}} \pm \mathrm{SE}$ & $\sigma^{2} d_{i}$ & $\mathrm{H}$ & $\mathrm{Q}^{+}$ & $\mathrm{Q}^{-}$ \\
\hline IC 39587 & 9.39 & $0.30 * \pm 0.10$ & 0.07 & $32.69^{\#}$ & 87.98 & $9.71^{\$}$ \\
\hline IC 39587 & $11.60 \mathrm{~s}$ & $-0.05^{*} \pm 0.26$ & $0.19 *$ & $56.87^{\#}$ & 18.29 & $23.43^{\$}$ \\
\hline IC 39550 & 8.40 & $0.12 \pm 0.33$ & $0.41 *$ & $78.73^{\#}$ & 55.35 & $29.74^{\$}$ \\
\hline IC 103059 & 11.00 & $0.07 * \pm 0.11$ & 0.08 & $32.73^{\#}$ & 31.84 & 19.16 \\
\hline IC 103190 & 8.26 & $0.36^{*} \pm 0.44$ & $0.43 *$ & $63.55^{\#}$ & 69.79 & $19.82^{\$}$ \\
\hline IC 103204 & 8.35 & $0.21 * \pm 0.19$ & $0.22 *$ & $57.32^{\#}$ & 32.94 & $22.36^{\$}$ \\
\hline IC 103204 & 11.51 & $-0.32 * \pm 0.17$ & $0.10^{*}$ & $34.57^{\#}$ & 23.81 & $20.64^{\$}$ \\
\hline IC 103207 & 10.55 & $-0.06^{*} \pm 0.15$ & 0.03 & $22.35^{\#}$ & 51.41 & 40.69 \\
\hline IC 103238 & 12.58 & $0.27 * \pm 0.14$ & 0.04 & $39.56^{\#}$ & 35.55 & 1.58 \\
\hline IC 103300 & 13.99 & $1.56^{*} \pm 0.23$ & $0.19 *$ & $51.54^{\#}$ & $32.14^{\$}$ & 23.44 \\
\hline IC 103785 & 11.08 & $0.03 * \pm 0.19$ & $0.09 *$ & $30.82^{\#}$ & 19.21 & $17.74^{\$}$ \\
\hline IC 103788 & 8.02 & $0.08 * \pm 0.16$ & $0.19 *$ & $49.37^{\#}$ & 28.94 & $24.71^{\mathrm{s}}$ \\
\hline IC 103788 & 10.10 & $-0.28 * \pm 0.21$ & $0.07 *$ & $34.65^{\#}$ & 22.44 & $14.18^{\$}$ \\
\hline IC 103821 & 9.85 & $0.09 * \pm 0.11$ & 0.09 & $29.84^{\#}$ & $19.26^{\$}$ & 17.65 \\
\hline IC 305292 & 8.01 & $0.09 * \pm 0.13$ & 0.02 & $28.67^{\#}$ & $18.08^{\S}$ & 21.37 \\
\hline IC 333153 & 12.23 & $0.29 \pm 0.23$ & $0.40^{*}$ & $74.11^{\#}$ & 48.45 & $33.97^{\$}$ \\
\hline IC 333213 & 8.10 & $-0.24 * \pm 0.22$ & $0.09 *$ & $46.57^{\#}$ & 42.49 & $17.68^{\$}$ \\
\hline IC 333213 & 14.71 & $1.05^{*} \pm 0.28$ & $0.27 *$ & $99.38^{\#}$ & 80.36 & $20.29^{\$}$ \\
\hline IC 338902 & 12.75 & $0.51 * \pm 0.33$ & $0.41 *$ & $77.87^{\#}$ & 67.04 & $32.60^{\$}$ \\
\hline IC 370739 & 13.58 & $0.23^{*} \pm 0.17$ & 0.01 & $28.14^{\#}$ & 41.83 & 8.071 \\
\hline Grand Mean & $.32 \pm 1.1$ & & & & & \\
\hline GM 4 & & & & & & \\
\hline
\end{tabular}

- Significant at $\mathrm{P}<0.05$; \# H was significant against $\mathrm{x}^{2} 0.05$ at $\mathrm{s}-\mathrm{ld}$, where $\mathrm{s}$ is the number of environments. \$ minimum of either $\mathrm{Q}^{+}$or $\mathrm{Q}^{-}$was significant against "e" value given by Gail and Simon (1985). 
Table.2 Accessions exhibiting significant *, \#H (heterogeneity of response), and $\mathrm{Q}^{+}$and $\mathrm{Q}^{-}$ against standard variety GM 4

\begin{tabular}{|c|c|c|}
\hline Characters & H & $\mathrm{Q}^{+}$and $\mathrm{Q}^{-}$ \\
\hline Seed yield/plant (g) & $\begin{array}{l}\text { All accessions } \\
\text { except IC } \\
325732, \text { IC } \\
333153 \text { and } \\
\text { EC } 520036\end{array}$ & $\begin{array}{l}\text { IC } 39550 \text {, IC } 39574 \text {, IC } 39587 \text {, IC } 103190 \text {, IC } 103204 \text {, } \\
\text { IC } 103219 \text {, IC } 103243 \text {, IC } 103245 \text {, IC } 103300 \text {, IC } \\
103785 \text {, IC } 103788 \text {, IC } 103821 \text {, IC } 418452 \text {, EC } \\
520034 \text {, EC 520035, EC 520036, IC } 285192 \text {, IC } \\
\text { 305292, IC } 311397 \text {, IC } 324021 \text {, IC } 325752 \text {, IC } 333153 \text {, } \\
\text { IC } 333213 \text {, IC } 338850 \text {, IC } 338902 \text {, IC } 369790 \text {, IC } \\
\text { 370714, IC } 373426 \text { G-492 and SML-668 } \\
\text { accessions) }\end{array}$ \\
\hline $\begin{array}{l}\text { Biological yield/ plant } \\
\text { (g) }\end{array}$ & $\begin{array}{l}\text { All accessions } \\
\text { except IC } \\
39583 \text { and IC } \\
103243\end{array}$ & 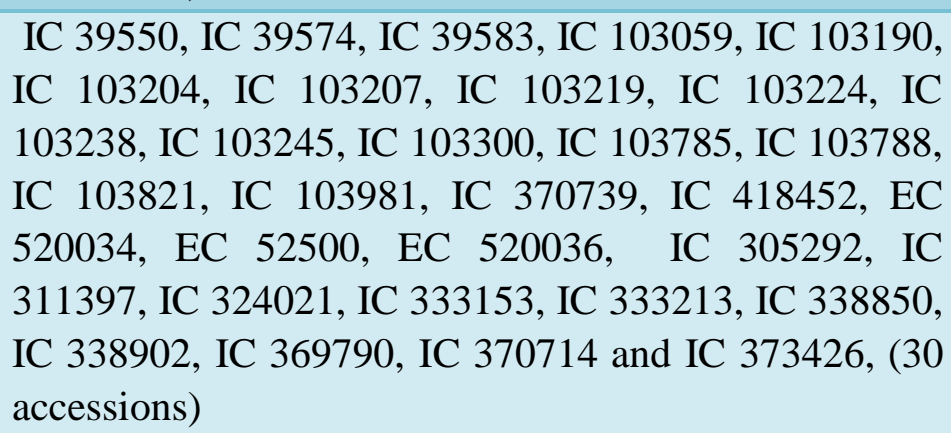 \\
\hline Harve & $\begin{array}{l}\text { All } 35 \\
\text { accessions }\end{array}$ & $\begin{array}{l}\text { IC } 39550 \text {, IC } 39574 \text {, IC } 39583 \text {, IC } 39587 \text {, IC } 103059 \text {, } \\
\text { IC } 103190 \text {, IC } 103204 \text {, IC } 103207 \text {, IC } 103219 \text {, IC } \\
103224 \text {, IC } 103238 \text {, IC } 103243 \text {, IC } 103245 \text {, IC } 103785 \text {, } \\
\text { IC } 103788 \text {, IC } 103821 \text {, IC } 103981 \text {, IC } 370739 \text {, IC } \\
418452 \text {, EC 520034, EC 52500, EC 520036, IC } \\
\text { 285192, IC 305292, IC 311397, IC 324021, IC 325752, } \\
\text { IC 333153, IC 338850, IC 338902, IC 369790, IC } \\
\text { 370714, IC 373426, G-492 and SML-668 }\end{array}$ \\
\hline Nun & $\begin{array}{l}\text { All } 37 \\
\text { accessions }\end{array}$ & $\begin{array}{l}\text { IC } 39574 \text {, IC } 39587 \text {, IC } 103059 \text {, IC } 103190 \text {, IC } \\
103204 \text {, IC } 103207 \text {, IC } 103219 \text {, IC } 103224 \text {, IC } 103243 \text {, } \\
\text { IC } 103785 \text {, IC } 103788 \text {, IC } 103821 \text {, IC } 370739 \text {, IC } \\
418452 \text {, EC 520034, EC 52500, EC 520036, IC } \\
305292 \text {, IC 324021, IC 325752, IC 333153, IC } 338850 \text {, } \\
\text { IC } 338902 \text {, IC 369790, IC } 370714 \text {, IC } 373426 \text { and } \\
\text { SML-668 (27 accessions). }\end{array}$ \\
\hline No. pods /plant & $\begin{array}{l}\text { All } 37 \\
\text { accessions }\end{array}$ & $\begin{array}{l}\text { IC } 39574 \text {, IC } 39587 \text {, IC } 103059 \text {, IC } 103190 \text {, IC } \\
103204 \text {, IC } 103219 \text {, IC } 103238 \text {, IC } 103245 \text {, IC } 103785 \text {, } \\
\text { IC } 103788 \text {, IC } 103821 \text {, IC } 103981 \text {, IC } 418452 \text {, EC } \\
520034 \text {, EC 52500, EC 520036, IC 324021, IC 325752, } \\
\text { IC 333153, IC 333213, IC 338850, IC 338902, IC } \\
369790 \text {, IC 370714, IC 373426 (25 accessions) }\end{array}$ \\
\hline No. of branches/ & All & IC 39550, IC 39574, IC 39587, IC 103190, IC 103204, \\
\hline
\end{tabular}




\begin{tabular}{|c|c|c|}
\hline plant & accessions & $\begin{array}{l}\text { IC } 103207 \text {, IC } 103219 \text {, IC } 103224 \text {, IC } 103243 \text {, IC } \\
103245 \text {, IC } 103785 \text {, IC } 103788, \text { IC } 103821 \text {, IC } 370739 \text {, } \\
\text { IC } 418452 \text {, EC 520034, EC 52500, EC 520036, IC } \\
\text { 285192, IC 305292, IC } 311397 \text {, IC } 324021 \text {, IC } 325752 \text {, } \\
\text { IC } 333153 \text {, IC } 333213 \text {, IC } 338850 \text {, IC } 338902 \text {, IC } \\
\text { 369790, IC 370714, G-492 and SML-668 } \\
\text { accessions) }\end{array}$ \\
\hline No. of pods/ cluster & $\begin{array}{l}\text { All } \\
\text { accessions }\end{array}$ & $\begin{array}{l}\text { IC } 39550 \text {, IC } 39574 \text {, IC } 39583 \text {, IC } 39587 \text {, IC } 103059 \text {, } \\
\text { IC } 103190 \text {, IC } 103204 \text {, IC } 103207 \text {, IC } 103219 \text {, IC } \\
103224 \text {, IC } 103238 \text {, IC } 103243 \text {, IC } 103245 \text {, IC } 103300 \text {, } \\
\text { IC } 103785 \text {, IC } 103788 \text {, IC } 103821 \text {, IC } 103981 \text {, IC } \\
370739 \text {, IC } 418452 \text { EC 520034, EC 52500, EC } \\
520036 \text {, IC } 285192 \text {, IC } 305292 \text {, IC } 311397 \text {, IC } 324021 \text {, } \\
\text { IC } 325752 \text {, IC } 333153 \text {, IC } 338850 \text {, IC } 338902 \text {, IC } \\
369790 \text {, IC } 370714 \text {, IC } 373426 \text {, G-492 and SML-668 } \\
\text { (26 accessions) }\end{array}$ \\
\hline 100-seed weight (g) & $\begin{array}{l}\text { All accessions } \\
\text { except IC } \\
103245\end{array}$ & $\begin{array}{l}\text { IC } 39587 \text {, IC } 103059 \text {, IC } 103190 \text {, IC } 103204 \text {, IC } \\
103207 \text {, IC } 103219 \text {, IC } 103224 \text {, IC } 103238 \text {, IC } 103243 \text {, } \\
\text { IC } 103785 \text {, IC } 103788 \text {, IC } 370739 \text {, IC } 418452 \text {, EC } \\
520034 \text {, EC 52500, EC 520036, IC 285192, IC } 305292 \text {, } \\
\text { IC } 311397 \text {, IC } 324021 \text {, IC } 325752 \text {, IC } 333213 \text {, IC } \\
338902 \text {, IC 370714, (24 accessions) }\end{array}$ \\
\hline
\end{tabular}

${ }^{*} \mathrm{H}$ was significant against $\mathrm{x}^{2} 0.05$ at s-1 df, where $\mathrm{s}$ is the number of environments. \# minimum of either $\mathrm{Q}^{+}$or $\mathrm{Q}^{-}$ was significant against "C" value given by Gail and Simmons (1985).

The presence of cross over interaction showed by the accessions IC 39574, IC 39587, IC 103059, IC 103190, IC 103204, IC 103219, IC 103238, IC 103245, IC 103785, IC 103788, IC 103821, IC 103981, IC 418452, EC 520034, EC 52500, EC 520036, IC 324021, IC 325752, IC 333153, IC 333213, IC 338850, IC 338902, IC 369790, IC 370714 , IC 373426 for number of pods per plant. The 31 accessions had the presence of cross over interaction for number of branches per plant were IC 39550, IC 39574, IC 39587, IC 103190, IC 103204, IC 103207, IC 103219, IC 103224, IC 103243, IC 103245, IC 103785, IC 103788, IC 103821, IC 370739, IC 418452, EC 520034, EC 52500, EC 520036, IC 285192, IC 305292, IC 311397, IC 324021, IC 325752, IC 333153, IC 333213, IC 338850, IC 338902, IC 369790, IC 370714, G-492 and SML-668. The 26 accessions expressed the presence of cross over interaction namely IC
39550, IC 39574, IC 39583, IC 39587, IC 103059, IC 103190, IC 103204, IC 103207, IC 103219, IC 103224, IC 103238, IC 103243, IC 103245, IC 103300, IC 103785, IC 103788, IC 103821, IC 103981, IC 370739, IC 418452, EC 520034, EC 52500, EC 520036, IC 285192, IC 305292, IC 311397, IC 324021, IC 325752, IC 333153, IC 338850, IC 338902, IC 369790, IC 370714, IC 373426, G-492 and SML-668 for number of pods per cluster. The 24 accessions IC 39587, IC 103059, IC 103190, IC 103204, IC 103207, IC 103219, IC 103224, IC 103238, IC 103243, IC 103785, IC 103788, IC 370739 , IC 418452, EC 520034, EC 52500, EC 520036, IC 285192, IC 305292, IC 311397, IC 324021, IC 325752, IC 333213, IC 338902, IC 370714 showed the presence of cross over interaction for test weight. However, most of the accessions expressed the presence of crossover interaction but all 
accessions failed to exhibit crossover interaction for all traits against GM 4 thus, presence or absence of crossover interaction was accession specific and trait specific (Rathore and Gupta, 1995). The accession IC 39550, IC 103300, IC103190, IC 39587 and IC 333213 in Kharif 2014; and IC 103785. IC 103204, IC 103788 and IC 333153, had significantly higher seed yield/plant than check GM 4 during kharif 2013.

The conclusion drawn from regression analysis and crossover and non-crossover interactions concept about identifying accessions having specific adaptability differs considerably. The accessions IC 103238, IC 103059, IC 103207, IC 370739, IC 333213 and IC 103300 identified as potential yielder having specific adaptability on the basis of regression analysis failed to exhibit significant $\min \left(\mathrm{Q}^{+}\right.$or $\left.\mathrm{Q}^{-}\right)$against standard variety GM 4 except IC 333213 and 103300 which had significant $\min \left(\mathrm{Q}^{+}, \mathrm{Q}^{-}\right)$ against GM 4. On the other hand the nine accessions IC 103785. IC 103204, IC 103788, IC 333153, IC103190, IC 338902, IC 39587 IC 333213 and IC 103300 were identified as potential yielders having specific adaptability on the basis of crossover and non-crossover interaction concept, failed to exhibit stable above average performance and responsiveness for seed yield/plant except IC 333213 and IC 103300.

A mention may be made of the accessions, IC 333213 and IC 103300, which have been identified as a high yielding ones having specific adaptability both by using regression analysis and crossover and non-crossover interaction concepts. These accessions gave significantly more mean seed yield/plant than the standard variety GM 4. However during 2013 these had insignificant lower seed yield than GM 4 Thus, accession IC 333213 and IC 103300 had specific adaptation rather than possessing general adaptation (Sharma, 1995).

\section{References}

Baker (1988). Test for crossover accessionenvironment interaction. Can. J. Plant SeL, 68 (4): 405-410.

Eberhart, S. A. and W. A. Russell (1966). Stability parameters for comparing varieties. Crop Sci., 6: 36-40.

Gail, M. and R. Simon (1985). Testing for quantitative interaction in Schizophyllum commune. analysis and character. Heredity., 27: 361-372.

Perkins, J. M. and J. L. Jinks (1968). Environmental and accessionenvironmental components of variability IV. Non-linear interaction for multiple inbred lines. Heredity., 23: 525-535.

Peto, R. 1982. Statistical aspects of cancer trials. pp. 867-871. In: E. E. Halnan (ed.), Treatment of cancer. Chapman and Hall, London, U.K.

Rathore, P. K. and V. P. Gupta (1995). Crossover and noncrossover interactions and regression analysis for seed yield and its components in pea. Crop Improv., 21: 14-18.

Sharma, R. K. 1995. Breeding lentil for response to additional nitrogen application. Crop Improv., 22: 139-141.

Virk, D. S. and B. K. Mangat (1991). Detection of crossover accession $\mathrm{x}$ environment interaction in pearlmillet. Euphytica., 52: 193-199.

\section{How to cite this article:}

Om Vir Singh, Neelam Shekhawat, Kartar Singh and Singh, A.K. 2018. Stability Analysis using Crossover GxE interaction in Mungbean [Vigna radiate (L.) R. Wilczek] in the hot -arid Climate of Rajasthan, India. Int.J.Curr.Microbiol.App.Sci. 7(07): 853-859.

doi: https://doi.org/10.20546/ijcmas.2018.707.104 